\title{
Impact of cis-acting elements' frequency in transcription activity in dicot and monocot plants
}

\author{
Ghada A. Abu El-Heba ${ }^{1}$ Gihan M. Hussein ${ }^{2} \cdot$ Inas F. Fahmy $^{3} \cdot$ Sara M. Abdou $^{2}$ • \\ Asmaa Faisal ${ }^{3} \cdot$ Omnia Taha $^{3} \cdot$ Naglaa A. Abdallah ${ }^{1,4}$
}

Received: 11 December 2014 / Accepted: 25 April 2015/Published online: 13 May 2015

(c) The Author(s) 2015. This article is published with open access at Springerlink.com

\begin{abstract}
The production of new cultivars via recombinant DNA technology is important in applied agriculture. Promoters play fundamental roles in successful transformation and gene expression. Fragments of the upstream regulatory region of the movement protein gene of the Tomato yellow leaf curl virus (TYLCV; two fragments) and Watermelon chlorotic stunt virus (WmCSV, two fragments) and one fragment of the coat protein putative
\end{abstract}

Ghada A. Abu El-Heba

ghadaahmed@hotmail.com

Gihan M. Hussein

gfn10@hotmail.com

Inas F. Fahmy

inas10@yahoo.com

Sara M. Abdou

sarahyoussef@hotmail.com

Asmaa Faisal

soka200675@yahoo.com

Omnia Taha

omnia_bio_agri@yahoo.com

Naglaa A. Abdallah

nabdallah@landesbioscience.com

1 Department of Nucleic Acid and Protein Structure, Agricultural Genetic Engineering Research Institute (AGERI), ARC, Giza, Egypt

2 Department of Gene Transfer, Agricultural Genetic Engineering Research Institute (AGERI), ARC, Giza, Egypt

3 Department of Microbial Molecular Biology, Agricultural Genetic Engineering Research Institute (AGERI), ARC, Giza, Egypt

4 Department of Genetics, Faculty of Agriculture, Cairo University, Giza, Egypt promoter of TYLCV (CPTY-pro) were isolated to assess their abilities to drive expression in monocot and dicot plants. We used bioinformatic analyses to identify tentative motifs in the fragments. The five promoter fragments were isolated, fused with the GUS reporter gene, and transformed into tomato, watermelon, and rice plantlets via Agrobacterium infiltration. GUS expression driven by each putative promoter was analysed using histochemical and fluorometric analyses. In both dicots and the monocots, the highest level of GUS expression was obtained using a truncated regulatory region from TYLCV (MMPTY-pro) followed by a truncated regulatory region from WmCSV (MMPWm-pro). However, the corresponding full-length fragments from TYLCV and WmCSV showed essentially equivalent expression levels in the fluorometric GUS assay compared with the enhanced Cauliflower mosaic virus e35S-pro. In addition, CPTY-pro showed no expression in either the dicots or the monocot. This study demonstrated that MMPTY-pro and MMPWm-pro may be useful as plant promoters.

Keywords Agrobacterium infiltration · GUS fluorometric assay $\cdot$ Putative promoters $\cdot$ Recombinant DNA technology - TYLCV $\cdot$ WmCSV

\section{Introduction}

In the last decades agriculture was considered to be biological machinery. With accumulative information of genetics, plant breeders have enhanced crop quality and yield. In this century recombinant DNA technology facilitated the characterization and isolation of valuable genes that can be introduced into living organisms to obtain new traits with improved qualities. 
Gene expression levels and patterns depend on the presence or absence of cis-regulatory elements in their promoter regions. Expression can be monitored experimentally using a reporter gene under control of the putative promoter. Promoters can be constitutive, inducible, or tissue-specific. Some geminivirus promoters are able to drive constitutive gene expression in transgenic plants, while others are subject to regulation. For example, the CP promoter from Tomato golden mosaic virus (TGMV) is active in both phloem and mesophyll cells in the presence of a transcriptional activator protein (TrAP).

Tomato yellow leaf curl virus (TYLCV) is a member of the genus Begomovirus in the family Geminiviridae (Briddon et al. 1996). Its monopartite single-stranded genome encodes five proteins from both the virion $(\mathrm{V})$ and complementary (C) strands: C1, C2, C3, V1, and V2. V1 and $\mathrm{V} 2$ are late-expression genes that code for the viral precoat and coat $(\mathrm{CP})$ proteins, respectively; $\mathrm{V} 2$ expression is transactivated by the $\mathrm{C} 2$ protein. $\mathrm{C} 1$, or REP, is a replication protein that recognizes the origin sequence (ori) in the viral genome (Laufs et al. 1995). C1 can positively regulate expression by binding to the viral replication enhancer protein, C3 (Settlage et al. 1996; Castillo et al. 2003). C2 is involved in CP expression regulation (Dry et al. 2000) and plays a role in viral systemic spread in plants.

The last open reading frame in the group of earlyexpression genes is c4-ORF, which encodes a movement protein (MP) that is responsible for viral movement from cell to cell through plasmodesmata. We previously reported that gene was highly expressed (Abu El-Heba et al. 1999), so we decided to isolate and evaluate the expression efficiency of its promoter and compare it with another geminivirus MP promoter and the widely used Cauliflower mosaic virus e35S promoter as a control.

We chose to isolate the MP promoter from the Watermelon chlorotic stunt virus (WmCSV), a bipartite geminivirus (Lecoq et al. 1994; Dafalla et al. 1998; Kheyr-Pour et al. 2000). Segment A of its genome contains the same genes as the TYLCV genome, except the MP BC1, which is incorporated within intergenic region of segment $\mathrm{B}$ (Orozco and Hanley-Bowdoin 1996).

In this study, the putative MP promoters of TYLCV (MP-TYLCV) and WmCSV (MP-WmCSV) were tested for their effects on the expression of the $\beta$-glucuronidase $(G U S)$ reporter gene. Agrobacterium infiltration was used to transform dicot and monocot plants with a promoterGUS construct to monitor promoter activity. Both promoters showed great promise for recombinant protein production.

\section{Materials and methods}

\section{Plant material}

To study the isolated promoter fragments, watermelon (Citrullus lanatus; Cucurbitaceae) cv. Gizal and tomato (Lycopersicon esculentum; Solanaceae) cv. CastleRock were used as model dicots, while rice (Oryza sativa; Poaceae) cv. Swat II was used as a monocot model. 5-day-old hypocotyledonous discs of watermelon and tomato were cultured as explants on MS medium (Murashige and Skoog 1962) supplemented with $1 \mathrm{mg} / \mathrm{L}$ 6-benzylaminopurine (BAP), 0.25 abscisic acid and $5 \mathrm{mg} / \mathrm{L} \mathrm{AgNO}_{3}$. Rice callus was initiated from seeds on MS medium containing $2 \mathrm{mg} / \mathrm{L}$ of 2,4-dichlorophenoxyacetic acid for 1 month.

\section{Culture incubation conditions}

All regeneration experiments were conducted in MS medium containing $30 \mathrm{~g} / \mathrm{L}$ sucrose and $8.0 \mathrm{~g} / \mathrm{L}$ agar, with a $\mathrm{pH}$ of 5.8 before autoclaving. All plant cultures were maintained in a growth chamber at $25^{\circ} \mathrm{C} \pm 2$ under fluorescent lights (8/16 h dark/light).

\section{Cloning the putative TYLCV and WmCSV promoters}

Figure 1 depicts the locations and the directions of the promoter fragments in the TYLCV (3 fragments) and WmCSV (2 fragments) genomes. These fragments represent the MP gene promoters in both viruses as well as the CP promoter gene of TYLCV (Table 1). To facilitate cloning of the fragments, the restriction sites for HindIII and $B g l I I$ were added to the $5^{\prime}$ and $3^{\prime}$ ends, respectively, of all MP promoters, and to the $3^{\prime}$ and $5^{\prime}$ ends, respectively, of $\mathrm{CP}$ promoters fragments.

For the putative MP promoters of both TYLCV and WmCSV, we designed specific primers to amplify both the entire putative promoter, respectively, called TMPTY-pro ( $\sim 570$ bp in size, specific primers PGLH and PGLB) (accession no. KP419702) and TMPWm-pro ( $750 \mathrm{bp}$, primers PEH1 and PEB1) (accession no. KP657700), and a smaller "minimal" fragment, respectively, called MMPTY-pro ( $300 \mathrm{bp}$, PGSH and PGSB) and MMPWmpro ( $\sim 550 \mathrm{bp}, \mathrm{PEH} 2$ and PEB2). One set of specific primers, $\mathrm{CPB}$ and $\mathrm{CPH}$, was used to amplify the $\mathrm{CP}$ promoter (CPTY-pro; $\sim 570 \mathrm{bp}$ in size). Table 2 showed the oligonucleotide sequences of all primers sets used to amplify the promoter fragments.

Plasmid pTYNA101 (Abdallah et al. 1993) containing the full genome of TYLCV-Egyptian strain (Eg) was the template for amplifying the different sized promoter 


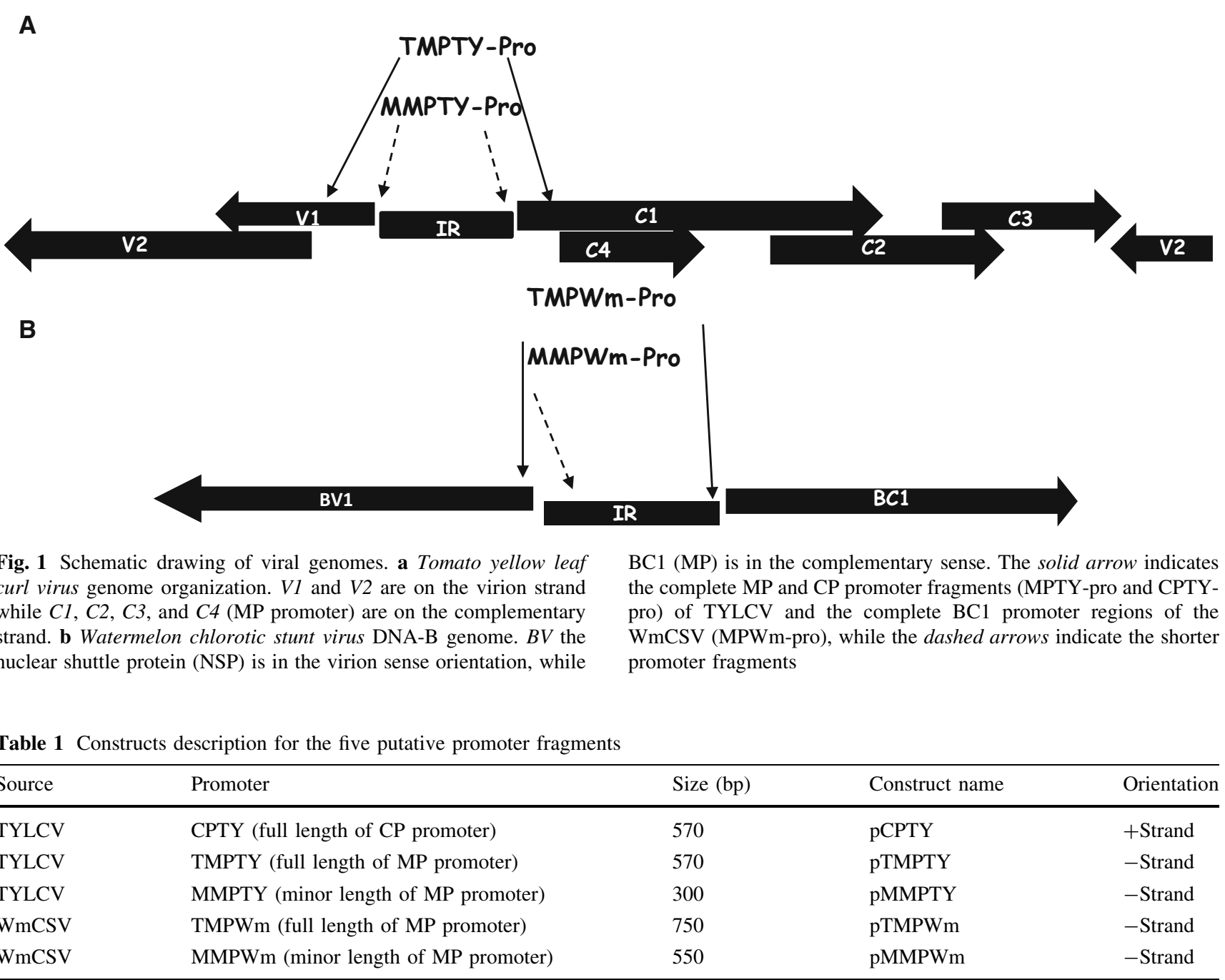

Table 2 Oligonucleotide primers used to amplify different sized promoter fragments from geminiviruses

\begin{tabular}{|c|c|c|}
\hline Oligonucleotides primers & Sequence & Restriction site added \\
\hline PGLH & $5^{\prime}$-CCCAAGCTTAGTCACGGGCCCTTACAAC-3' & HindIII \\
\hline PGLB & 5'GAAGATCTGGAGATGTGGTTCCCCATTC- $3^{\prime}$ & $B g l I I$ \\
\hline PGSH & $5^{\prime}$-СCCAAGCTTATTGCAAGACAAAATACTT- $3^{\prime}$ & HindIII \\
\hline PGSB & $5^{\prime}$ - GAAGATCTATTTTAAATAAACGAGGCAT-3' & $B g l \mathrm{II}$ \\
\hline $\mathrm{CPB}$ & $5^{\prime}$-GAAGATCTAGTCACGGGCCCTTACAAC- $3^{\prime}$ & $B g l \mathrm{II}$ \\
\hline $\mathrm{CPH}$ & $5^{\prime}$-CCCAAGCTTGGAGATGTGGTTCCCCATTC- $3^{\prime}$ & HindIII \\
\hline PEH1 & $5^{\prime}$-CCCAAGCTTGGGACGTACGTCCCGTCACA-3' & HindIII \\
\hline PEB1 & $5^{\prime}$-GAAGATCTTCTCCGTTCTTCCACAGGACC- $3^{\prime}$ & $B g l I I$ \\
\hline $\mathrm{PEH} 2$ & $5^{\prime}$-CCCAAGCTTAATATTATAGGATGGCC-3' & HindIII \\
\hline PEB2 & $5^{\prime}$-GAAGATCTTCTCCGTTCTTCCACAGGACC- $3^{\prime}$ & $B g l \mathrm{II}$ \\
\hline
\end{tabular}

fragments of TYLCV. Restriction-digested (HindIII$B g l$ II) fragments were individually cloned into the plasmid pMONRTG (Liu 2003) from which the $35 \mathrm{~S}$ promoter had been excised, creating a GUS reporter gene under the control of the promoter fragment, i.e. two sizes of the MP promoter and one size of the $\mathrm{CP}$ promoter. The three pro::GUS constructs were excised using HindIII and EcoRI and ligated into a modified pCAMBIA1390 binary vector after excision of its $35 \mathrm{~S}$ promoter. 
Purified WmCSV preparations of the Sudan isolate (Kheyr-Pour et al. 2000) were used as a template for amplifying the different sized promoter fragments of WmCSV. Each restriction-digested (HindIII-BglII) promoter fragment was cloned into pMONRTG after the excision of its $35 \mathrm{~S}$ promoter to yield a GUS reporter gene under the promoter's control. The two constructs, TMPWm-pro::GUS and MMPWm-pro::GUS, were released from the vector using HindIII and BamHI. These fragments were then ligated into a modified pCAMBIA1390 binary vector after excising its e35S promoter.

\section{Bioinformatics analyses}

Subsequently, the five promoter fragments were sequenced using an ABI 3730xl sequencer (Applied Biosystems, Foster City, CA, USA), after cloning in pGEM-T Easy (Promega, Fitchburg, WI, USA). These sequences and that of the e35S promoter were analysed using Web Signal Scan (http://www.dna.affrc.go.jp/PLACE/signalscan.html) (Prestridge 1991).

\section{Agrobacterium strains and constructs}

The five promoter constructs and pCAMBIA3301 were transformed into Agrobacterium strain GV3101 (Koncz and Schell 1986) by electroporation (Sukharev et al. 1992) for explant agroinfiltration. A construct with GUS under the control of the e35S promoter (GV3101::pCAMBIA3301) was used as a positive control for the GUS reporter gene. The five constructs each harboured the GUS gene in pCAMBIA1390 under control of a test promoter fragment: the large (GV3101::TMPTY-pro) or small (GV3101::MMPTY-pro) fragment of the TYLCV MP promoter; or the large (GV3101::TMPWm-pro) or small (GV3101::MMPWm-pro) fragment of the WmCSV-MP promoter. GV3101 was used a negative control.

\section{Agrobacterium infiltration}

Agroinfiltration was carried out on watermelon, tomato, and rice explants. Agrobacterium cultures were grown overnight at $28{ }^{\circ} \mathrm{C}$ in liquid LB medium supplemented with $50 \mathrm{mg} / \mathrm{L}$ kanamycin and $10 \mathrm{mg} / \mathrm{L}$ rifampicin. When cultures reached about 0.8 at $\mathrm{OD}_{600}$, cells were harvested and diluted by re-suspending and incubating in MES buffer (10 mM MES/KOH, pH 5.6 and $10 \mathrm{mM} \mathrm{MgCl}_{2}$ ) for $2 \mathrm{~h}$ at room temperature to a final concentration of 1.0 at $\mathrm{OD}_{600}$. Tomato, watermelon, and rice explants were submerged separately in one of the seven Agrobacterium-suspension cultures and placed inside desiccators for infiltration at $200 \mathrm{mbar}$ for $5 \mathrm{~min}$. The infiltrated explants were incubated in the dark and assayed for GUS activity after 3 days.

\section{Detection of GUS expression}

GUS expression was visually evaluated using the histochemical assay of Jefferson et al. (1987). The GUS reaction was performed 3 days post-agroinfiltration by incubating the samples with GUS buffer solution containing $1 \mathrm{mM}$ 5-bromo-4-choloro-3-indolyl- $\beta$-glucuronic acid overnight at $37{ }^{\circ} \mathrm{C}$. The blue colour was detected visually by the naked eye and using a light microscope (LEICA Icc 50 HD-DM750, Wetzlar, Germany) after bleaching the chlorophyll with $70 \%$ ethanol.

\section{Quantitative GUS assay}

A quantitative fluorescent assay was performed to evaluate GUS expression using the substrate 4-methylumbelliferylgalactopyranoside (MUG) and the FluorAce ${ }^{\mathrm{TM}} \beta$-glucuronidase Reporter Assay Kit (Bio-Rad, Hercules, CA, USA). Protein was extracted from each sample, with five replicates for each putative promoter in each type of explant (tomato, watermelon and rice). Each sample $(5 \mu \mathrm{g})$ was incubated with $1 \mathrm{mM}$ MUG buffer at $37^{\circ} \mathrm{C}$ for $15 \mathrm{~min}$. Stop buffer $(1 \times)$ was used to terminate the reaction. The fluorescent molecule 4-methylumbelliferone (4MU) was released by hydrolysis of the fluorogenic substrate by GUS. Fluorescence of 4MU was measured with a Versafluor fluorometer (Bio-Rad) using an emission wavelength of $460 \mathrm{~nm}$ and an excitation wavelength of $360 \mathrm{~nm}$. A fresh preparation of $100 \mathrm{nM} 4 \mathrm{MU}$ was used as a calibration standard. GUS activity was then calculated as the production of $4 \mathrm{MU}$ from $\mathrm{MUG}$ in $\mathrm{pmol} / \mathrm{min} / \mu \mathrm{g}$ of protein. The mean GUS activity from the e35S promoter of pCAMBIA3301 was considered to be $100 \%$ and used to standardize the activities from promoters in other constructs.

\section{Results}

\section{Isolation, sequencing, and analysis of promoter fragments}

Dissection analysis of the five promoter regions isolated from TYLCV and WmCSV can assist in identifying cisacting signals and their interactions with trans-acting factors that contribute to eukaryotic gene expression. The isolated fragments were amplified using specific primers, cloned, and sequenced. The sequences were analysed for the presence of $c i s$-acting elements that could affect transcription efficiency. The resulting motifs were counted and their loci recorded.

The motifs in the five promoter regions and their frequencies were compared with those of e35S-pro (Fig. 2). 


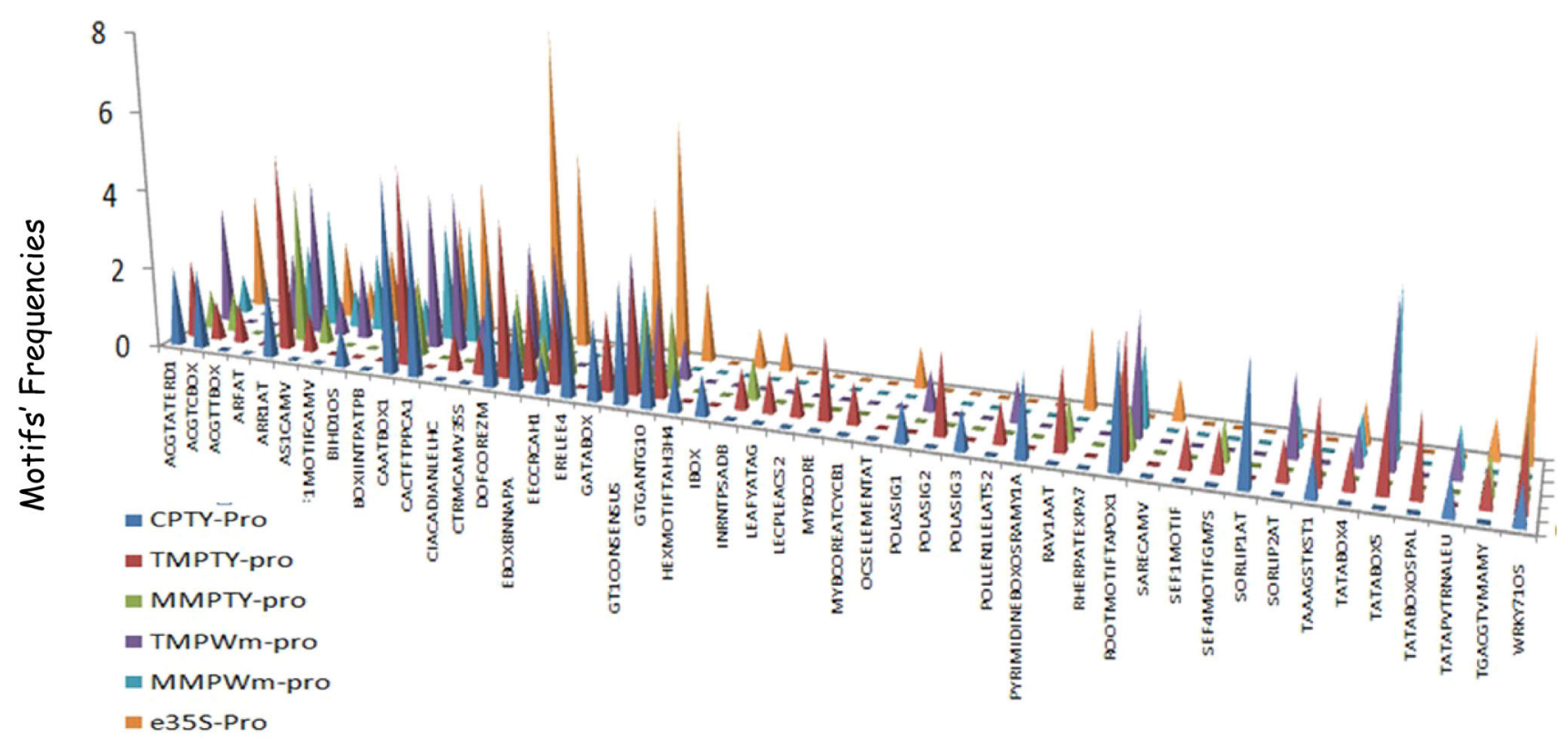

Conserved Domains

Fig. 2 Conserved motif frequencies in putative promoters CPTY-pro, TMPTY-pro, MMPTY-pro, TMPWm-pro, MMPWm-pro and e35S-pro

Fig. 3 Cloning of the putative promoter fragments into modified pCambia 1390 binary vector by replacing the e35S promoter to drive GUS expression

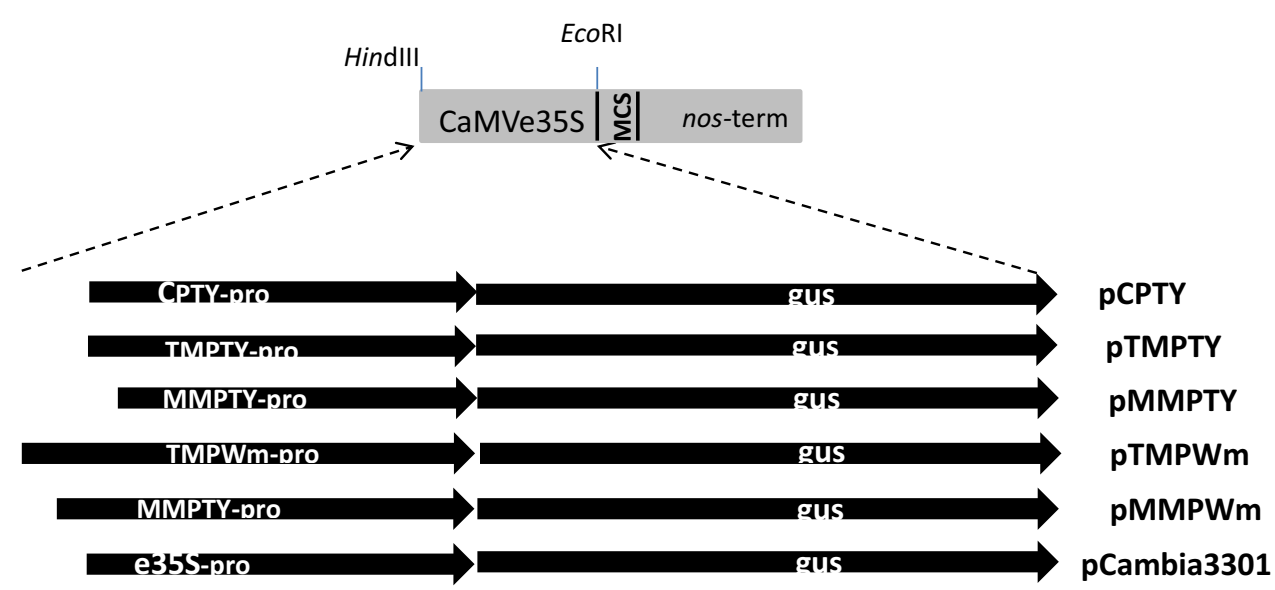

To investigate the efficiencies of the regulatory regions, the fragments were cloned into a modified pCAMBIA1390 binary vector to replace the e35S promoter driving GUS expression (Fig. 3). Agroinfiltration was used to introduce the constructs into tomato, watermelon plantlets and rice callus to test the promoter efficiencies in dicots and a monocot.

\section{In silico identification of regulatory motifs and data analysis}

In silico comparisons of the orthologous promoter fragments were performed using Web Signal Scan. Five conserved motifs were detected in all five putative promoters as well as the e35S promoter: ACGTATERD1 $\left(5^{\prime}\right.$ ACGT-3'), ARR1AT (5'-NGATT-3') (Sakai et al. 2000), CAATBOX1 (5'-CAAT-3'), DOFCOREZM (5'-AAAG-3') (Yanagisawa and Schmidt 1999), and GATABOX (5'GATA- $3^{\prime}$ ). Their positions and frequencies in our putative promoter fragments are shown in Table 3.

Bioinformatics analysis also revealed unique cis-elements in some fragments: CPTY-pro contained ERELEE4 (5'-AWTTCAAA-3') at positions 266, 273, and 280 URR; HEXMOTIFTAH3H4 (5'-ACGTCA-3') at position 376 URR; PYRIMIDINEBOXOSRAMY1A (5'-CCTTTT- $\left.3^{\prime}\right)$ at positions 337 and $343 \mathrm{URR}$; and SORLIP1AT 
Table 3 Positions and the frequencies of the five conserved motifs present in CPTY-pro, TMPTY-pro, MMPTY-pro, TMPWm-pro, MMPWmpro and e35S-pro

\begin{tabular}{|c|c|c|c|c|c|c|c|}
\hline Domain & Consensus & CPTY-pro & TMPTY-pro & MMPTY-pro & TMPWm-pro & $\begin{array}{l}\text { MMPWm- } \\
\text { pro }\end{array}$ & e35S-pro \\
\hline ACGTATERD1 & ACGT & 2 sites & 2 sites & 1 site & 3 sites & 1 site & 3 sites \\
\hline $\begin{array}{l}\text { Position in } \\
\text { URR }\end{array}$ & & 376,410 & 376,410 & 242 & $490,726,730$ & 490 & $396,407,447$ \\
\hline Percentage & & 4 & 4 & 6 & 6 & 3 & 5 \\
\hline ARR1AT & NGATT & 2 sites & 5 sites & 4 sites & 4 sites & 3 sites & 2 sites \\
\hline $\begin{array}{l}\text { Position in } \\
\text { URR }\end{array}$ & & 587,513 & $\begin{array}{l}164,288,293,391 \text {, } \\
502\end{array}$ & $\begin{array}{l}30,154,159 \\
257\end{array}$ & $\begin{array}{l}111,225,306, \\
658\end{array}$ & $\begin{array}{l}111,225 \\
306\end{array}$ & 224,424 \\
\hline Percentage & & 4 & 8 & 15 & 8 & 10 & 4 \\
\hline CAATBOX1 & CAAT & 5 sites & 5 sites & 2 sites & 3 sites & 2 sites & 3 sites \\
\hline $\begin{array}{l}\text { Position in } \\
\text { URR }\end{array}$ & & $\begin{array}{l}99,265,390,467 \\
572\end{array}$ & $\begin{array}{l}67,101,261,397 \\
578\end{array}$ & 127,263 & $231,434,692$, & 231,434 & $85,180,464$ \\
\hline Percentage & & 9 & 8 & 7 & 8 & 10 & 5 \\
\hline DOFCOREZM & AAAG & 3 sites & 4 sites & 2 sites & 3 sites & 2 sites & 8 sites \\
\hline $\begin{array}{l}\text { Position in } \\
\text { URR }\end{array}$ & & $73,178,300$ & $85,338,344,433$ & 204,210 & $21,387,598$ & 21,387 & $\begin{array}{l}10,46,152,174,198 \\
271,308,313,353 \\
389\end{array}$ \\
\hline Percentage & & 6 & 6 & 7 & 6 & 6 & 14 \\
\hline GATABOX & GATA & 2 sites & 2 sites & 1 site & 3 sites & 2 sites & 4 sites \\
\hline $\begin{array}{l}\text { Position in } \\
\text { URR }\end{array}$ & & 106,416 & 200,607 & 66 & $257,425,642$ & 257,425 & $155,262,305,434$ \\
\hline Percentage & & 4 & 3 & 4 & 6 & 6 & 7 \\
\hline
\end{tabular}

$\left(5^{\prime}-\mathrm{GCCAC}-2^{\prime}\right)$ at positions 583, 581, and 619 URR. Both TMPTY-pro and MMPTY-pro contained RAV1AAT $\left(5^{\prime}-\mathrm{CACCA}-3^{\prime}\right)$ at positions 154 and 611 URR and 20 URR, respectively; ARFAT (5'-TGTCTC- $\left.3^{\prime}\right)$ at positions 405 and 445 URR. TMPWm-pro and MMPWm-pro both contained BOXIINTPATPB (5'-ATGAGAA-3 $\left.{ }^{\prime}\right)$ at position 422 URR.

In TMPTY-pro and MMPTY-pro (Fig. 4a, b), the ARR1AT represented 8 and $15 \%$ of the promoter fragment lengths, respectively. The motifs CAATBOX1, DOFCOREZM, EECCRCAH1 (5'-GANTTNC-3'), GT1CONSENSUS (5'-GRWAAW-3'), GTGANTG10 (5'-GTGA-3'), WRKY71OS $\left(5^{\prime}\right.$-TGAC- $\left.3^{\prime}\right)$ each represented $7 \%$ of MMPTY-pro and 8,6, 3, 5, and $3 \%$, respectively, of TMPTY-pro. Each of the other motifs comprised $4 \%$ of MMPTY-pro and 2-5\% in TMPTY-pro. In TMPWm-pro and MMPWm-pro (Fig. 4c, d), the TATABOX5 comprised $13 \%$ of MMPWm-pro and $8 \%$ of TMPWm-pro. The motifs CAATBOX1, ARR1AT, and CACTFTPPCA1 (5'YACT- $3^{\prime}$ ) each made up $10 \%$ of MMPWm-pro and $8 \%$ of TMPWm-pro. Other motifs differed only slightly.

TATABOX4, TATABOX5, and TATABOXOSPAL were detected in TMPTY-pro, while they were completely absent in MMPTY-pro. TATABOX4 and TATABOX5 were recorded in TMPWm-pro and MMPWm-pro. Table 4 shows the distribution of TATA boxes within the five promoter regions and e35S-pro. Remarkably, CPTY-pro harboured the highest number of the cis-acting elements within its DNA sequence among the promoter regions (data are not shown).

\section{Histochemical GUS assays}

To determine the expression levels of each putative promoter, tomato, watermelon, and rice were infiltrated with the five prepared constructs. Histochemical GUS assays were performed 3 days after Agrobacterium infiltration. The assays revealed different intensities of blue GUS activity among the TMPTY-pro, MMPTY-pro, TMPWm-pro, MMPWm-pro, and e35S-pro constructs in all tested tissues, while CPTY-pro yielded no GUS activity. MMPTY-pro, the minor fragment of the MP promoter of TYLCV, showed the highest intensity blue colour. The expression pattern of each putative promoter was monitored in transverse sections of infiltrated tomato tissues. Blue staining with MMPTY-pro was observed clearly in vascular bundle as well as the palisade mesophyll and spongy mesophyll (Fig. 5b, c). MMPWm-pro showed the next highest intensity of GUS activity, with blue staining in xylem and phloem cells and in secondary vascular bundles (Fig. 5e). Expression of TMPTY-pro and TMPWm-pro was detected in mature xylem and phloem cells of the infiltrated tomato 
A

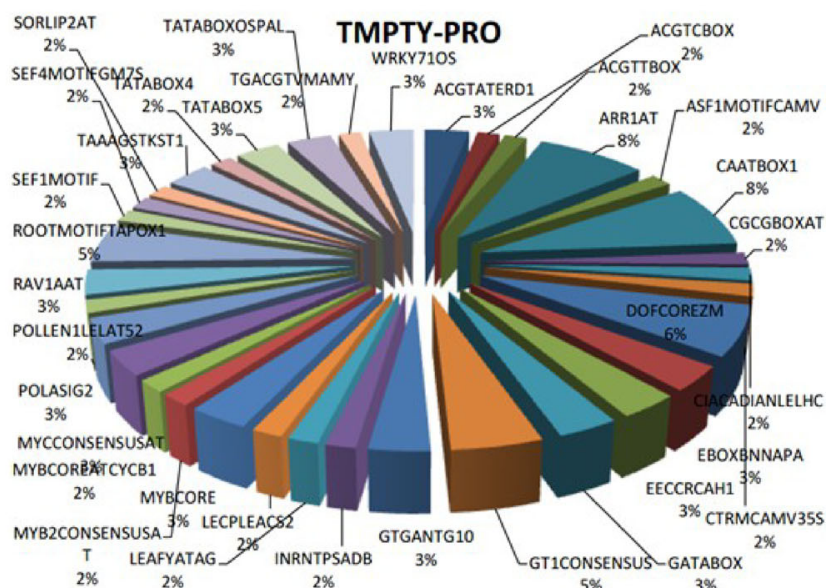

C

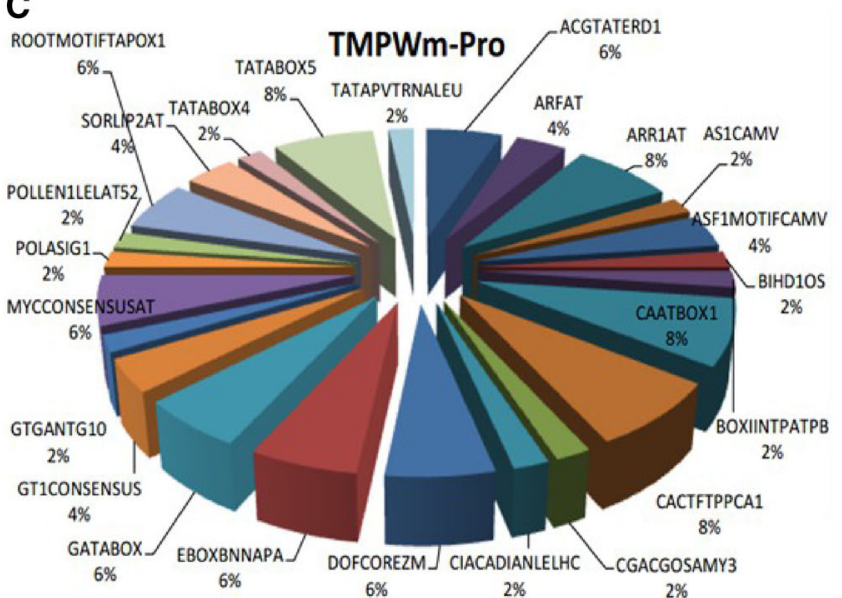

Fig. 4 Composition of the promoters. a TMPTY-pro contained 59 conserved boxes; CAATBOX1 had the highest frequency $(8 \%)$. b MMPTY-pro comprised 26 conserved boxes, and ARR1AT was the

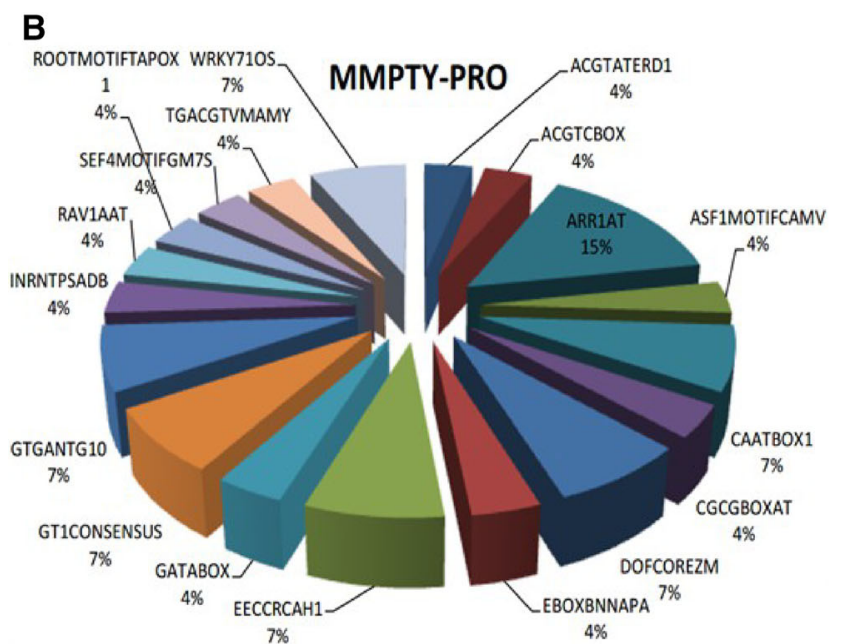

D

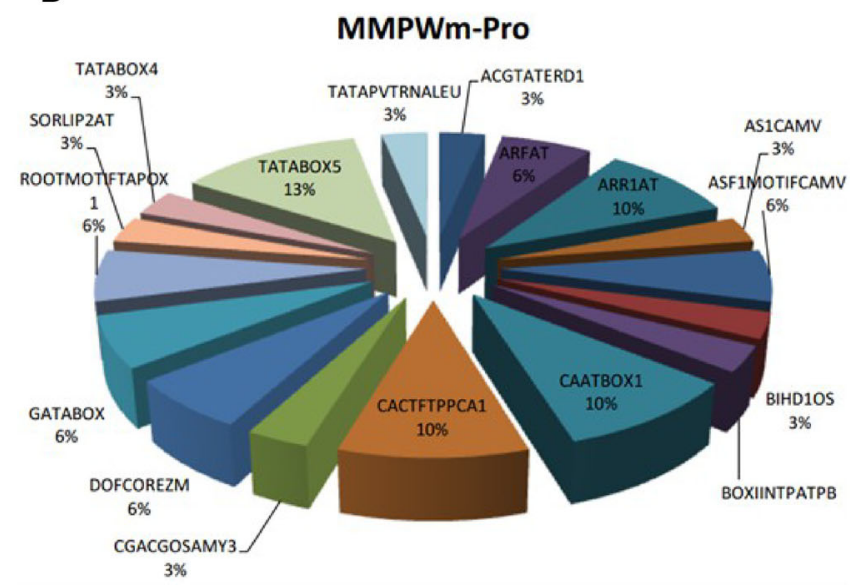

most frequent (15\%). c TMPWm-pro had 48 conserved, with the most frequent being CAATBOX1 (8\%). d MMPWm-pro included 31 conserved boxes; TATABOX5 had the highest frequency (13\%)

Table 4 TATA box distributions and frequencies within CPTY-pro, TMPTY-pro, MMPTY-pro, TMPWm-pro, MMPWm-pro and the e35S promoter

\begin{tabular}{llllllll}
\hline Domain & Consensus & CPTY-pro & TMPTY-pro & MMPTY-pro & TMPWm-pro & MMPWm-pro & e35S-pro \\
\hline TATABOX4 & TATATAA & - & 1 site & - & 1 site & 1 site & 1 site \\
Position in URR & & - & 435 & - & 117 & 496 & 2 \\
Percentage & & 0 & 2 & 0 & 2 & 4 sites & 4 sites \\
TATABOX5 & TTATTT & - & 2 sites & - & $124,169,329,368$ & $124,169,329,368$ & - \\
Position in URR & & - & 117,140 & - & 8 & 13 & - \\
Percentage & & 0 & 3 & 0 & - & - & - \\
TATABOXOSPAL & TATTTAA & - & 2 sites & - & - & 0 & - \\
Position in URR & & - & 138,535 & - & 0 & & 0 \\
Percentage & & 0 & 3 & 0 & &
\end{tabular}

tissues (Fig. 5d, f), with a similar intensity to the e35S promoter (Fig. 5a). Although CPTY-pro harboured the most cis-acting elements within its length, it did not promote GUS expression in any of the plants.

\section{Quantitative GUS assay}

To precisely determine the expression level of each putative promoter, quantitative fluorometric assays were done 
Fig. 5 Histochemical localization of GUS transient expression. a pCambia3301. b, c PMMPTY. d pTMPTY. e pMMPWm. f pTMPWm. All sections are transverse leaf sections of transformed tomato explants. $v b$ vascular bundle, $x$ xylem, $p$ phloem, $e p$ external phloem, ip internal phloem, $v$ vein, $p m$ palisade mesophyll, $s m$ spongy mesophyll, $s v b$ secondary vascular bundle. Bar 10, 20, $100 \mu \mathrm{m}$

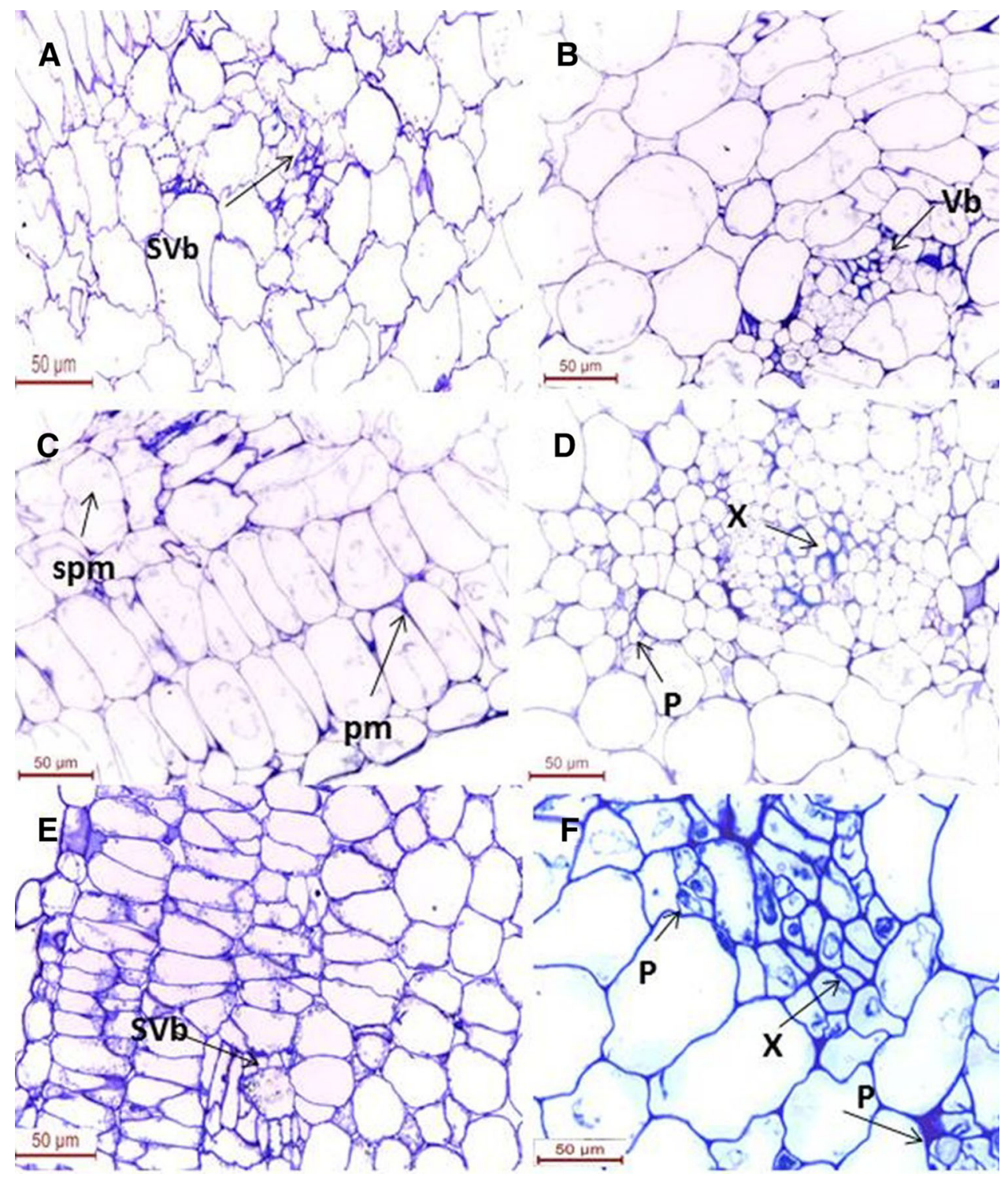

to measure promoter efficiency in driving $G U S$ in tomato, watermelon, and rice. Five replicates of each promoter in each type of explant were subjected to this assay. 3 days post-agroinfiltration, the mean values of the replicates were calculated and plotted (Fig. 6). CPTY-pro was not analysed because it showed no activity during the histochemical GUS assay.

In general, MMPTY-pro and MMPWm-pro had higher GUS expression levels than the longer fragments TMPTYpro and TMPWm-pro in both dicot and monocot plants. Moreover, the minor fragment MMPTY-pro showed higher expression than the minor fragment MMPWm-pro. The e35S promoter activity was lowest among the putative promoters in the monocot plant.

In tomato, which is the main host of TYLCV, the highest GUS activity was driven by the truncated promoter MMPTY, followed by MMPWm-pro, then e35S-pro and
TMPTY-pro (with nearly equal activities), and finally TMPWm-pro (Fig. 6a). In watermelon, the main host of WmCSV, GUS had the highest level of expression when driven by MMPTY-pro, followed by MMPWm-pro, TMPTY-pro, and TMPWm-pro and e35S (with nearly identical levels; Fig. 6b). Rice was used to evaluate these promoters in monocots; GUS assays indicated that the highest level of expression was obtained when the gene was controlled by MMPTY-pro, followed by MMPWmpro, TMPTY-pro, TMPWm-pro, and finally e35S (Fig. 6c).

\section{Discussion}

Promoters are regulatory regions that control gene expression in eukaryotes, which require exceptionally precise systems to regulate complex expression patterns involving 
A

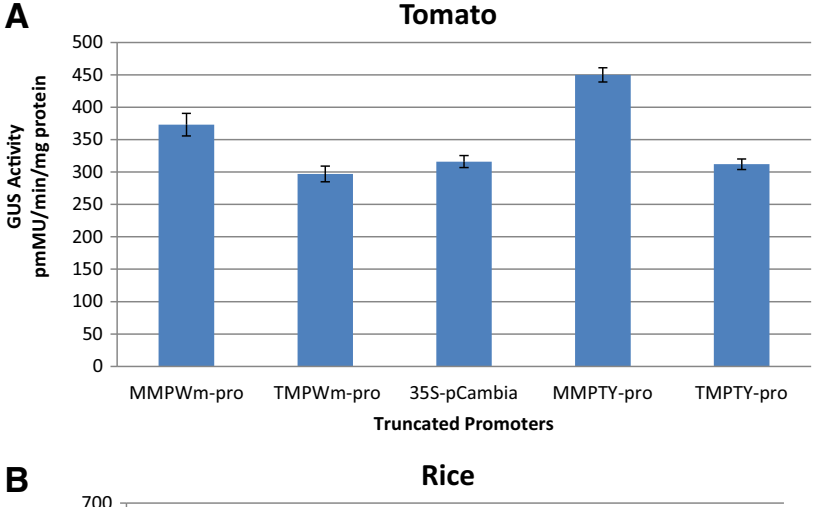

B

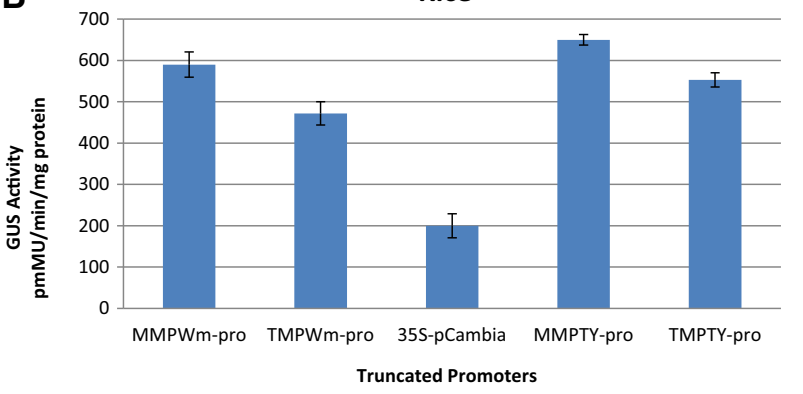

C

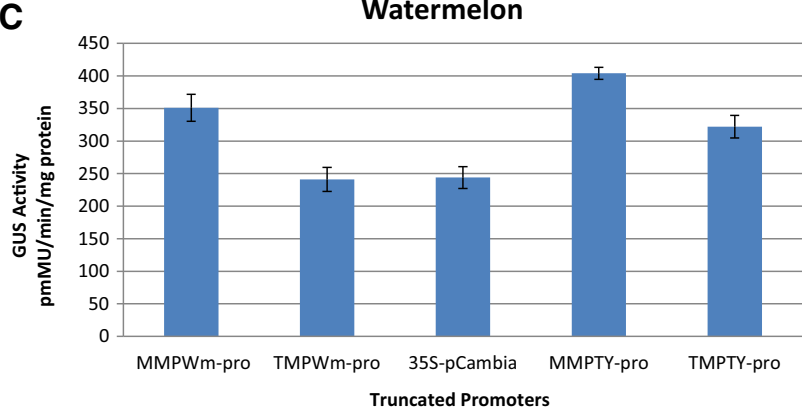

Fig. 6 Quantitative fluorometric assay for the truncated promoters in a tomato, the main host for TYLCV; $\mathbf{b}$ watermelon, the main host for WmCSV; and c rice, a monocot

thousands of genes (McKenna and O'Malley 2002a, b; Narlikar et al. 2002; Orphanides and Reinberg 2002). The promoters of plant viruses have great potential for plant biotechnology to engineer recombinant proteins with higher yields rapidly and at large scales (Pogue et al. 2002). Viruses such as Potato virus $X$, Tobacco mosaic virus (TMV), Alfalfa mosaic virus, Cucumber mosaic virus, and Cowpea mosaic virus have been used as expression vectors to produce recombinant proteins, like vaccine antigens (Donson et al. 1991; Chapman et al. 1992; Yusibov et al. 1997; Lomonossoff and Hamilton 1999; Zhao et al. 2000; Sanchez-Navarro et al. 2001; Pogue et al. 2002; Yusibov and Rabindran 2004).

The more basic knowledge we have on fundamental transcription elements in active promoters, the more efficient in vitro transcription we can perform in the future. Plant promoters that are activated precisely when and where needed would be ideal for genetic engineering.
Therefore, the isolation and characterization of new effective functional plant promoters is highly desirable. To advance this goal, five putative promoter regions were isolated from two geminiviruses with bidirectional gene transcription from a stretch of DNA containing the core promoter region.

By comparing the different cis-elements present in each of our putative promoters and the promoters' quantitative fluorescent GUS assays, we were able to make some valuable observations, which will significantly enhance future research on promoter architectures and activities. MMPTY-pro, which conferred the highest level of GUS expression, had the fewest conserved motifs (26 cis-acting elements), followed by MMPWm-pro (31). Although CPTY-Pro had the most elements, it did not promote expression. Interestingly, although CPTY-pro is a TATA-less promoter, this fact did not explain its behaviour, this observation is consistent with the observation of Khan et al. 2015) when it has observed a weak activity of CLCuBuV $\mathrm{CP}$ promoter which has been explained to probably be due to the absence of $A C 2$ gene product in $\mathrm{CLCuBuV}$ (Amrao et al. 2010). The role of transactivator $A C 2$ protein for activation of virion sense promoter which has already been reported (Hong et al. 1996 and Sunter et al. 1990) and may have a great effect on the activity of $\mathrm{CP}$ promoter. Gene expression process in geminivirus happens by an early expression of complimentary sense gene, whose products are then participating in viral replication such as $A C l$ (Rep) or they may act as transcription activator for the virion sense gene expression, such as $A C 2$ (TrAp). In contrast, the expression of virion sense genes usually appears later and requires complimentary sense gene product/products for activation (Ashraf et al. 2014). We have observed that the MMPTY-pro, which had the highest expression levels, was TATA-less like the CP which means that the TATA box had no great effect on the promoter activity in our case.

TATABOXes (TATABOX4, TATABOX5, TATABOXOSPAL) comprised $2 \%$ of e35S-pro, $16 \%$ of MMPWm-pro, $10 \%$ of TMPWm-pro, and $8 \%$ of TMPTY-pro. With TATABOX-dependent core promoters, the transcription factors (TFs) can assemble into a preinitiation complex in the following order: TFIID, TFIIB, RNA polymerase II-TFIIF complex, TFIIF, and then TFIIH. TFIID consists of TBP (TATA box-binding protein) and about 13 TBP-associated factors (Burley and Roeder 1996; Albright and Tjian 2000; Berk 2000; Verrijzer 2001; Tora 2002), while TFIIB is single polypeptide that interacts with TBP as well as DNA upstream of the TATA box. In TATA-less promoters (e.g. CPTY-pro and MMPTY-pro), DPE is the downstream core promoter binding site of TFIID (Burke and Kadonaga 1996).

Remarkably the brightest blue colour of GUS promoted by MMPTY-pro, the TATA-less promoter, was observed 
constitutively in vascular bundles, spongy mesophyll, palisade mesophyll, and in the green plastids within palisade cells of tomato leaves. This result agrees with Erb and van Nimwegen (2011), who stated that TATA-less promoters are expressed in a constitutive manner and enriched for house-keeping genes, whereas TATA-containing promoters show variability in expression, and are often induced in response to stress. Our other putative promoters showed different expression patterns within plant tissues. The GUS staining derived from pMMPWm, with the second most intense levels, occurred in mature xylem and phloem, as well as in secondary vascular bundles. This staining was restricted to mature xylem and phloem in pTMPTY, pTMPWm, and pCAMBIA3301.

The activity results proved that the smaller fragments of the promoters were more efficient than their larger corresponding fragments. Comparing both activity level and the cis-acting elements present within the small MMPTY-pro and the large TMPTY-pro, we found that ARR1AT, GT1CONSENSUS, GTGANTG10, ACGTATERD1, WRKY71OS, EECCRCAH1, and ASF1MOTIFCAMV comprised $15,7,7,4,7,7$, and $4 \%$, respectively, of MMPTY-pro and 8, 5, 3, 3, 3, 3, and $2 \%$, respectively, of TMPTY-pro. In the WmCSV promoter fragments, TATABOX5, ARR1AT, CAATBOX1, CACFTPPCA1, ARFAT, and ASF1MOTIFCAMV made up 10, 10, 10, 10, 6 , and $6 \%$, respectively, of the small MMPWm-pro and 8 , $8,8,8,4$, and $4 \%$, respectively, of the large TMPWm-pro. Therefore, we postulate that the frequency of some cisacting elements within the promoter region plays a crucial role in the promoter's efficiency.

In this study, ARR1AT BOX, which comprised $15 \%$ of MMPTY-pro and $8 \%$ of TMPTY-pro, may have had a positive effect on the promoter's efficiency. This motif made up $10 \%$ of MMPWm-pro and $8 \%$ of TMPWm-pro. ARR1 belongs to the MYB TF family and is one of seven members in the largest subclass of type-B ARRs (Sakai et al. 2000; Imamura et al. 2003; Tajima et al. 2004; Taniguchi et al. 2007). The MYP TF family is present in all eukaryotes. All members have the N-terminus MYP DNAbinding domain (Nero et al. 2009). ARR1 mediates cytokinin signal responses (Sakai et al. 2000, 2001; Hwang and Sheen 2001). Therefore, increasing the frequency of the ARR1AT BOX within our putative truncated promoters map explain the elevated GUS activity in both of our minor fragment promoters. Because BAP was used as a cytokinin source in all of our tissue cultures, it acted as a positive signal that enhanced the response of the ARR1 DNAbinding domain to the ARR1AT BOX. Consequently, the GUS expression was considerably increased by the truncated putative promoters.

ASF1MOTIFCAMV is another element that made up a greater percentage of the promoter region in both
MMPTY-pro (4\%) and MMPWm-pro (6\%) compared with TMPTY-pro (2\%) and TMPWm-pro (4\%), respectively. This motif comprised $4 \%$ of the e35S promoter and reacts with the ASF-1 cellular factor (Lam et al. 1989).

Another element, WRKY71OS, is a member of the W-BOX. WRKY is one of the largest transcriptional regulator families in the plant kingdom and is considered as an essential part of the signalling pathways that moderates many plant processes. WRKYs are proposed to perform a regulatory role in resistance transcriptome amid the W-box element $[(\mathrm{C} / \mathrm{T}) \mathrm{TGAC}(\mathrm{C} / \mathrm{T}]$ (Eulgem and Somssich 2007), and an enormous number of WRKY genes are up-regulated by pathogen infection (Maleck et al. 2000; Dong et al. 2003; Glazebrook et al. 2003; Kalde et al. 2003; Eulgem and Somssich 2007). Specific WRKY proteins have been proven to regulate plant immune responses. Arabidopsis WRKY52/RRS1 helps in defence against the Ralstonia solanacearum bacterium. Another Arabidopsis WRKY70 acts as a positive regulator of salicylic acid-dependent defence mechanisms ( $\mathrm{Li}$ et al. 2004, 2006). Therefore, elevating the frequency of WRKY1OS in MMPTY-pro may be another mechanism to enhance GUS expression, because the Agrobacterium that we used to introduce our constructs into the explants is considered to be a biotic stress that can induce the WRKY TFs to initiate immune signalling cascades by binding to their proper element, in this case WRKY1OS.

In contrast, our analysis found that MYBCORATCYCB, MYCCONSESUSAT, MYB2CONSENSHSA MYBCORE, POLLEN1LELAT52, SEF1MOTIF, LEAFYATAG, LECPLEACS2, and POLASIG2 had been completely deleted from MMPTY-pro, while MYCCONSESUSAT, POLLEN1LELAT52, POLASIG1, GTGANTG10, and GT1CONSENSUS had been completely deleted from MMPWm-pro, although they were present in the longer versions of these promoters. This result suggested that the deletion of some elements could decrease the competition of different TFs for their specific elements within the promoter region.

The five conserved domains ARR1AT, CAATBOX1, ACGTATERD1, GATABOX, and DOFCOREZM were common in all of our putative promoters and in the $35 \mathrm{~S}$ promoter. CAATBOX1 occupies a considerable proportion of our putative promoter fragments: $10 \%$ in MMWm-pro, $9 \%$ in CPTY-pro, $8 \%$ in TMPWm-pro and TMPTY-pro, $7 \%$ in MMPTY-pro, and finally $5 \%$ within e35S. This motif is responsible for the tissue-specific promotion of the pea legumin gene LegA (Shirsat et al. 1989) and occurs within the pvPDF promoter. The ACGTATERD1 domain is required for etiolation-induced expression of erdl (early response to dehydration) in Arabidopsis. GATABOXes are required for high-level light-regulated and tissue-specific gene expression. GATA TFs are a group of DNA-binding 
proteins distinguished by a zinc finger motif that have been implicated in light- and nitrate-dependent transcription control (Reyes et al. 2004). GATA TFs are reported to bind the CaMV 35S promoter and are conserved in cab promoters as well (Lam et al. 1989). DOFCOREZM is the target binding site of Dof proteins, which are specific DNA-binding proteins associated with the expression of multiple genes in plants. Dof proteins also differentially regulate diverse promoters in a variety of plant tissues (Yanagisawa and Schmidt 1999).

Gene expression, and thus protein biosynthesis, does not depend only on the presence of functional cis-elements, but also on how and when the trans-acting elements interact with their proper elements and also on the activity of RNA polymerase II. The transcriptome activation of CPTY-pro is mediated by transactivation of the $\mathrm{C} 2$, which might explain the silent expression of this putative promoter.

\section{Conclusions}

The information that we have elucidated on the begomoviral promoter of TYLCV and WmCSV, a very distinct Old World and newly emerged begomovirus, would help in further elucidating transcription regulation in begomoviruses. Thus, generating more efficient tools in producing transgenes.

ARR1AT, GT1CONSENSUS, GTGANTG10, ACGTATERD1, WRKY71OS, EECCRCAH1, ASF1MOTIFCAMV, TATABOX5, CAATBOX1, CACFTPPCA1 and ARFAT might be strong candidates for enhancing transcription. The constitutive expression profile of MMPTY-pro can be explained by the fact that it is a TATAless promoter. In future work, we intend to investigate the capability of these recommended motifs to enhance promoter activity for large-scale in vitro protein production.

Acknowledgments We thank Dr. Pascal Ratet, ISV, CNRS, Gifsur-Yvette, France, for providing the pCAMBIA3301 and modified pCAMBIA1390 and Dr. Stephan Winter, DSMZ, Braunschweig, Germany, for providing purified WnCSV (Sudan isolate). The Web interface for Signal Scan was kindly provided by Ms. Meena Sakharkar at Bioinformatics Centre, NUS, Singapore.

Conflict of interest The authors declare that they have no conflict of interest in the publication.

Open Access This article is distributed under the terms of the Creative Commons Attribution 4.0 International License (http:// creativecommons.org/licenses/by/4.0/), which permits unrestricted use, distribution, and reproduction in any medium, provided you give appropriate credit to the original author(s) and the source, provide a link to the Creative Commons license, and indicate if changes were made.

\section{References}

Abdallah NA, Aref N, Fauquel M, Madkour M, Beachy RN (1993) Nucleotide sequence and genome organization of an infectious DNA clone of tomato yellow leaf curl virus isolated from Egypt. In: IXth international congress of virology, 8-13 August 1993, Glasgow

Abu El-Heba GA, Abdallah NA, Aref N, Abdelsalam ET (1999) Molecular and serological studies on some gene functions of Geminivirus group. M.Sc. thesis, Cairo University

Albright SR, Tjian R (2000) TAFs revisited: more data reveal new twists and confirm old ideas. Gene 242:1-13

Amrao L, Amin I, Shahid MS, Briddon RW, Mansoor S (2010) Cotton leaf curl disease in resistant cotton is associated with a single begomovirus that lacks an intact transcriptional activator protein. Virus Res 152:153-163. doi:10.1016/j.virusres.2010.06. 019

Ashraf MA, Shahid AA, Rao AQ, Bajwa KS, Husnain T (2014) Functional characterization of a bidirectional plant promoter from cotton leaf curl Burewala virus using an Agrobacteriummediated transient assay. Viruses 6:223-242. doi:10.3390/ v6010223

Berk AJ (2000) TBP-like factors come into focus. Cell 103:5-8

Briddon RW, Bedford ID, Tsai JH, Markham PG (1996) Analysis of the nucleotide sequence of the treehopper-transmitted geminivirus, tomato pseudo-curly top virus, suggests a recombinant origin. Virology 219:387-394

Burke TW, Kadonaga JT (1996) Drosophila TFIID binds to a conserved downstream basal promoter element that is present in many TATA-box-deficient promoters. Genes Dev 10:711-724

Burley SK, Roeder RG (1996) Biochemistry and structural biology of transcription factor IID (TFIID). Annu Rev Biochem 65:769-799

Castillo AG, Collinet D, Deret S, Kashoggi A, Bejarano ER (2003) Dual interaction of plant PCNA with geminivirus replication accessory protein (REn) and viral replication protein (Rep). Virology 312:381-394

Chapman S, Kavanagh T, Baulcombe D (1992) Potato virus $X$ as a vector for gene expression in plants. Plant J 2:549-557

Dafalla GA, Gronenborn B, Kheyr-Pour A, Lecoq FL (1998) Watermelon chlorotic stunt virus: a new emerging epidemic in export melons in Sudan. In: Second international workshop geminiviurses, San Juan, Puerto Rico. The American Phytopathology Society (APS), San Jose, Puerto Rico, p 37

Dong J, Chen C, Chen Z (2003) Expression profiles of the Arabidopsis WRKY gene superfamily during plant defence response. Plant Mol Biol 51:21-37

Donson J, Kearney CM, Hilf ME, Dawson WO (1991) Systemic expression of a bacterial gene by a tobacco mosaic virus-based vector. Proc Natl Acad Sci USA 88:7204-7208

Dry I, Krake L, Mullineaux P, Rezaian A (2000) Regulation of tomato leaf curl virus gene expression in host tissues. Mol PlantMicrobe Interact 13:529-537

Erb I, van Nimwegen E (2011) Transcription factor binding site positioning in yeast: proximal promoter motifs characterize TATA-less promoters. PLoS One 6(9):e24279

Eulgem T, Somssich IE (2007) Networks of WRKY transcription factors in defence signalling. Curr Opin Plant Biol 10:366-371

Glazebrook J, Chen W, Estes B, Chang H-S, Nawrath C, Metraux J-P, Zhu T, Katagiri F (2003) Topology of the network integrating salicylate and jasmonate signal transduction derived from global expression phenotyping. Plant J 34:217-228 
Hong Y, Saunders K, Hartley MR, Stanley J (1996) Resistance to geminivirus infection by virus-induced expression of dianthin in transgenic plants. Virology 220:119-127 PMID

Hwang I, Sheen J (2001) Two-component circuitry in Arabidopsis cytokinin signal transduction. Nature 413:383-389

Imamura A, Kiba T, Tajima Y, Yamashino T, Mizuno T (2003) In vivo and in vitro characterization of the ARR11 response regulator implicated in the His-to-Asp phosphorelay signal transduction in Arabidopsis thaliana. Plant Cell Physiol 44:122-131

Jefferson RA, Kavanagh TA, Bevan MW (1987) GUS fusions: betaglucuronidase as a sensitive and versatile gene fusion marker in higher plants. EMBO J 6(13):3901-3907

Kalde M, Barth M, Somssich IE, Lippok B (2003) Members of the Arabidopsis WRKY group III transcription factors are part of different plant defence signalling pathways. Mol Plant Microbe Interact 16:295-305

Khan ZA, Abdin MZ, Khan JA (2015) Functional characterization of a strong bi-directional constitutive plant promoter isolated from cotton leaf curl Burewala virus. PLoS One 10(3):e0121656. doi:10.1371/journal.pone.0121656

Kheyr-Pour A, Bananej K, Dafalla GA, Caciagli P, Noris E, Ahoonmanesh A, Lecoq H, Gronenborn B (2000) Watermelon chlorotic stunt virus from the Sudan and Iran: sequence comparisons and identification of a whitefly-transmission determinant. Phytopathology 90:629-635

Koncz C, Schell J (1986) The promoter of $T_{L}$-DNA gene 5 controls the tissue-specific expression of chimaeric genes carried by a novel type of Agrobacterium binary vector. Mol Gen Genet 204:383-396

Lam E, Benfey PN, Gilmartin PM, Fang RX, Chua NH (1989) Sitespecific mutations alter in vitro factor binding and change promoter expression pattern in transgenic plants. Proc Natl Acad Sci 86(20):7890-7894

Laufs J, Traut W, Heyraud F, Matzeit V, Rogers SG, Schell J, Gronenborn B (1995) In vitro cleavage and joining at the viral origin of replication by the replication initiator protein of tomato yellow leaf curl virus. Proc Natl Acad Sci USA 92:3879-3883

Lecoq H, Dafalla GA, Mohamed YF, Pitrat M, Omara SE, Ali HA (1994) A survey cucurbit viruses in Kordofan, east and central regions of Sudan Khartoum. Univ J Agric Sci 1:47-71

Li J, Brader G, Palva ET (2004) The WRKY70 transcription factor: a node of convergence for jasmonate-mediated and salicylatemediated signals in plant defence. Plant Cell 16:319-331

Li J, Brader G, Kariola T, Palva ET (2006) WRKY70 modulates the selection of signalling pathways in plant defence. Plant $\mathrm{J}$ $46: 477-491$

Liu J (2003) Sea ice climatology: variations and teleconnections: observational and modeling studies. Ph.D. thesis, Columbia University

Lomonossoff GP, Hamilton WD (1999) Cowpea mosaic virus-based vaccines. Curr Top Microbiol Immunol 240:177-189

Maleck K, Levine A, Eulgem T, Morgan A, Schmid J, Lawton KA, Dangl JL, Dietrich RA (2000) The transcriptome of Arabidopsis thaliana during systemic acquired resistance. Nat Genet 26:403-410

McKenna NJ, O'Malley BW (2002a) Combinatorial control of gene expression by nuclear receptors and coregulators. Cell 108:465-474

McKenna NJ, O'Malley BW (2002b) Combinatorial control of gene expression by nuclear receptors and coregulators. BMC Bioinform 2009(10):435

Murashige T, Skoog F (1962) A revised medium for rapid growth and bioassays with tobacco tissue cultures. Physiol Plant 15:473-497
Narlikar GJ, Fan H-Y, Kingston RE (2002) Cooperation between complexes that regulate chromatin structure and transcription. Cell 108:475-487

Nero D, Katari M, Kelfer J, Tranchina D, Coruzzi G (2009) In silico evaluation of predicted regulatory interactions in Arabidopsis thaliana. BMC Bioinform 10:435

Orozco BM, Hanley-Bowdoin L (1996) A DNA structure is required for geminivirus replication origin function. $\mathrm{J}$ Virol 70(1):148-158

Orphanides G, Reinberg D (2002) A unified theory of gene expression. Cell 108:439-451

Pogue GP, Lindbo JA, Garger SJ, Fitzmaurice WP (2002) Making an ally from an enemy: plant virology and the new agriculture. Annu Rev Phytopathol 40:45-74

Prestridge D (1991) Information on SIGSCAN is maintained at the Advanced Biosciences Computing Center. University of Minnesota, Minneapolis

Reyes JC, Muro-Pastor MI, Florencio FJ (2004) The GATA family of transcription factors in Arabidopsis and rice. Plant Physiol 134(4):1718-1732

Sakai H, Aoyama T, Oka A (2000) Arabidopsis ARR1 and ARR2 response regulators operate as transcriptional activators. Plant $\mathrm{J}$ 24:703-711

Sakai H, Honma T, Aoyama T, Sato S, Kato T, Tabata S, Oka A (2001) ARR1, a transcription factor for genes immediately responsive to cytokinins. Science 294:1519-1521

Sanchez-Navarro J, Miglino R, Ragozzino A, Bol JF (2001) Engineering of alfalfa mosaic virus RNA 3 into an expression vector. Arch Virol 146:923-939

Settlage SB, Miller B, Hanley-Bowdoin L (1996) Interactions between geminivirus replication proteins. J Virol 70:6790-6795

Shirsat A, Wilford N, Croy R, Boulter D (1989) Sequences responsible for the tissue specific promoter activity of a pea legumin gene in tobacco. Mol Gen Genet 215(2):326-331

Sukharev SI, Klenchin VA, Serov SM, Chernomordik LV, Chizmadzhev YuA (1992) Electroporation and electrophoretic DNA transfer into cells. The effect of DNA interaction with electropores. Biophys J 63(5):1320-1327

Sunter G, Hartitz MD, Hormuzdi SG, Brough CL, Bisaro DM (1990) Genetic analysis of tomato golden mosaic virus: ORF AL2 is required for coat protein accumulation while ORF AL3 is necessary for efficient DNA replication. Virology 179:69-77

Tajima Y, Imamura A, Kiba T, Amano Y, Yamashino T, Mizuno T (2004) Comparative studies on the type-B response regulators revealing their distinctive properties in the His-to-Asp phosphorelay signal transduction of Arabidopsis thaliana. Plant Cell Physiol 45:28-39

Taniguchi M, Sasaki N, Tsuge T, Aoyama T, Oka A (2007) ARR1 directly activates cytokinin response genes that encode proteins with diverse regulatory functions. Plant Cell Physiol 48:263-277

Tora L (2002) A unified nomenclature for TATA box binding protein (TBP)-associated factors (TAFs) involved in RNA polymerase II transcription. Genes Dev 16:673-675

Verrijzer CP (2001) Transcription factor IID—not so basal after all. Science 293:2010-2011

Yanagisawa S, Schmidt RJ (1999) Diversity and similarity among recognition sequences of Dof transcription factors. Plant $\mathrm{J}$ 17(2):209-214

Yusibov V, Rabindran S (2004) Plant viral expression vectors: history and developments. In: Fischer R, Schillberg S (eds) Molecular farming. Wiley-VCH Verlag GmbH and Co. KgaA, Weinheim, pp 77-90 
Yusibov V, Modelska A, Steplewski K, Agadjanyan M, Weiner D, Hooper DC, Koprowski H (1997) Antigens produced in plants by infection with chimeric plant viruses immunize against rabies virus and HIV-1. Proc Natl Acad Sci USA 94:5784-5788
Zhao Y, Hammond J, Tousignant ME, Hammond RW (2000) Development and evaluation of a complementation-dependent gene delivery system based on cucumber mosaic virus. Arch Virol 145:2285-2295 